\title{
Covid-19: UK trade talks with EU must not hinder cooperation in tackling threat, BMA warns
}

\author{
Abi Rimmer
}

The BMJ

A post-Brexit trade agreement between the UK and the European Union must maximise cooperation to ensure that pandemic threats such as covid-19 can be tackled effectively, the BMA has said.

The BMA's chair of council, Chaand Nagpaul, said in a letter to the UK prime minister, Boris Johnson, that any agreement must not reduce the ability of UK organisations and the European Centre for Disease Prevention and Control to cooperate for the benefit of patients.

Nagpaul acknowledged Johnson's statement that the comprehensive free trade agreement would not include "any regulatory alignment." But he warned that regulatory divergence risked raising trade barriers that could disrupt the flow of essential health supplies and severely limit the UK's ongoing ability to collaborate closely with the European Medicines Agency.

Nagpaul's letter said, "As such collaboration helps deliver timely access to innovative medicines and medical devices for our patients, and maintain robust pharmacovigilance systems, we would urge your government to pursue an agreement which maximises these levels of cooperation for the benefits of patients in the UK and across Europe."
As more than 22000 qualified doctors from the European Economic Area are currently licensed in the UK, the BMA also urged Johnson's negotiating team to secure "a pathway for the mutual recognition of professional qualifications" so that qualification requirements do not become "an unnecessary barrier" to the UK's ability to recruit and retain doctors from Europe.

The BMA said it was imperative that the agreement did not restrict future governments' freedom to develop reforms to the NHS and to the interface between health and social care, towards a more collaborative model.

The letter concluded, "Having been explicit about the damaging consequences that a 'no deal' Brexit will have for patients, the health workforce and health services across both the UK and Europe, we note with concern that the ambitious timeline for completion of the negotiations means these fears are still held.

"Therefore, I urge your government to secure a CFTA

[comprehensive free trade agreement] with the EU that permits our members' continued treatment of their patients to the highest possible level beyond the end of the transition period." 